\title{
Hot physics in the Cold War
}

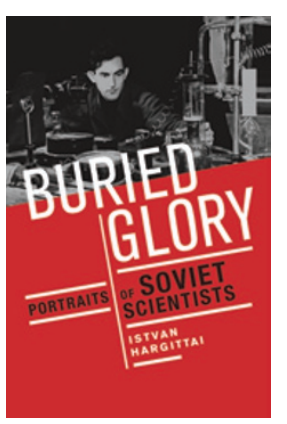

\author{
Buried Glory: \\ Portraits of Soviet \\ Scientists \\ By Istvan Hargittai \\ OXFORD UNIV. PRESS: \\ 2013. 352PP. US $\$ 35.00$
}

stvan Hargittai's book, Buried Glory, is a hagiography ('lives of saints') of fourteen Soviet scientists of the Cold War era, making most of them sound more like Mother Teresa than like Albert Einstein or Richard Feynman. As the title indicates, the author feels that their great contributions (mostly to physics) have gone unrecognized. This is a remarkable inference, given that half of them (Igor Tamm, Nikolai Semenov, Lev Landau, Petr Kapitza, Alexei Abrikosov, Vitaly Ginzburg and Andrei Sakharov) were awarded Nobel Prizes.

The book is highly readable and offers some insights (undocumented) into their personal lives, but it unfortunately strays into old areas of polarized opinions and controversial history: for example, the developments of hydrogen bomb technology credited to Sakharov (or even worse, to Edward Teller, about whom Hargittai previously wrote a controversial biography) were largely due to Stan Ulam, as indeed his still-classified, single-authored work shows. This is now known by much of the scientific community - based on numerous published histories - as is the fact that no hydrogen bomb designed by Teller ever worked. Thus referring to the "Teller-Ulam model" or to Teller as the proverbial "father of the hydrogen bomb" is mythology, not history. Ulam is never mentioned in this book, which is odd as he and the author (like Teller) are Hungarian. He clearly invented many of Sakharov's "discoveries". And crediting Sakharov with re-discoveries that may have been based on espionage is hardly appropriate without further documentation.

Similar ill-advised excursions by the author include repeated credit to Tamm for discovering phonons in 1929. Phonons are quantized vibrational waves, and their "discovery" is partly semantics: quantized scattering from phonons was probably discovered by Raman in 1928 or Brillouin in 1922, but as quantization only began to be understood after de Broglie in 1924, it is moot to attribute phonons to Tamm in 1929, especially as his noted paper on phonons appeared in 1932. Russians have always aggressively maintained that this was all predicted by Mandelshtam in 1918, but he only published his ideas in 1926, and credit in science generally goes with publication date, not clever ideas. Perhaps worst of all in the context of "buried glory" is the discussion of the Cherenkov effect - many Soviet physicists of that era have spoken of Cherenkov as "the dumbest person to win a Nobel Prize in physics", pointing out that the observation was a complete accident, that he did not understand the effect, and that "he did not understand the effect even after Tamm explained it to him". So much for buried glory.

There is a great deal of discussion about those who were elected to the Russian Academy of Sciences as full or corresponding members. The author seems surprised that these elections are often based in part on politics or criteria other than academic accomplishments. Yet this seems equally true in the USA in 2013 as in the USSR in the 1950s. In both the US National Academy of Sciences and the UK Royal Society members are explicitly asked to consider gender and geographic location as priorities, as opposed to scientific merit.

As to who got buried in Novodevichy Cemetery - well, it was my pleasure to tour it (a rare privilege in 1981), and Hargittai finds it extremely valuable as a sign of national respect. But I cannot imagine that being buried in a prominent Orthodox Christian cemetery would have been important to Ginzburg, for example.

The chapters on Kapitza, Landau and Evgeny Lifshits are insightful and balanced. Kapitza was larger than life. His disdain for Sergey Vavilov could be clarified somewhat; it is downplayed - in actuality he refused to use the Institute stationery as Vavilov's name was on the letterhead. And Lifshits was certainly more of a genuine collaborator with Landau than scribe. Landau's marriage to Kora was not exactly as the author describes: he writes that "When they married, they gave each other full freedom." That is misleading; as described in Kora's recent biography, she was rather monogamous, whereas Lev was a serial philanderer.

It is interesting that the author mentions Landau's condescending misunderstanding of Dirac's antiparticles (although Dirac himself initially mistook his anti-electrons for protons), and perhaps more interesting that he remarks on Landau's publication of his own students' work. This was not uncommon among Soviet-era physicists, with Ginzburg publishing the so-called Ginzburg criterion for fluctuation phenomena as sole author in 1960, despite it being published in detail a year earlier by his student Arkadiy Levanyuk. Such lapses in scientific ethics would not have gone unnoticed or unpunished in the West.

There are a few eccentricities in the book. The suggestion that V. S. Letokhov should have shared Chu's Nobel Prize is just silly. Letokhov's work (mostly on laser separation of isotopes) was not of the same rank in science, and this example shows the author's prejudices. Similarly, leaving Gorkov out of the Nobel Prize shared by Abrikosov has not been widely viewed as controversial. Other questionable comments include the reason for Abrikosov's second divorce - it was not that his wife "became homesick for France." The two parted ways with great animosity that was totally unrelated to homesickness. Abrikosov stayed with my wife and me in Boulder, Colorado, for a few days in 1991 when he emigrated to the USA and gave a very different account. The author is very critical of Abrikosov and suggests that "he and his wife might find themselves quite lonely" in their twilight years in the USA. I assure him that many of us in the West valued our friendship with Abrikosov, and he has indeed made friends outside Russia.

All societies like having saints. One should not confuse great physics with a pious life. Feynman and Oppenheimer had complex personal lives and were not saints; don't confuse that with evaluations of their great work. Writing a book about Russian physics and physicists should not be an excuse for lionizing the ones you liked personally or feigning worry about the retirement years of those you didn't.

\section{REVIEWED BY JAMES F. SCOTT}

James F. Scott is at the Cavendish Laboratory, University of Cambridge, J. J. Thomson Road, Cambridge CB3 OHE, UK.

e-mail: jfs32@cam.ac.uk 